\title{
Application of statistical techniques to evaluate the reliability of ultrasonic and rebound hammer measurements of compressive strength in the concrete of bridges
}

\author{
C. H. Carvalho ${ }^{1 *}$, J. B. Severo Junior ${ }^{2}$, M. C. S. S. Macedo ${ }^{3}$, S. Griza ${ }^{3}$, C. E. C. de Andrade ${ }^{3}$, A. $^{2}$ \\ A. dos Santos ${ }^{3}$ and L. S. Barreto ${ }^{3}$ \\ ${ }^{1}$ Federal Institute of Sergipe, Graduate Program in Materials Science and Engineering of the Federal University of \\ Sergipe - UFS, Brazil. \\ ${ }^{2}$ Department of Chemical Engineering, Federal University of Sergipe - UFS, Brazil. \\ ${ }^{3}$ Department of Materials Science and Engineering, Federal University of Sergipe - UFS. Federal University of Sergipe, \\ Marechal Rondon ave, Jardim Rosa Elze, São Cristovão, Zip Code: 49100-000, Sergipe, Brazil.
}

Received 22 December, 2013; Accepted 10 March, 2014

\begin{abstract}
In order to assess the uncertainties in the experimental measurements, the use of statistical error analysis is essential for a reliable technical diagnosis on structural safety in reinforced concrete of bridges. Two non-destructive techniques (ultrasound and rebound hammer) were performed, resulting in conflicting technical diagnostics when analyzed without the study of the variability of experimental errors. It was evident that physically the only use of arithmetic average means nothing. The obtained results also demonstrated the lack of correlations between those ones driven by the ultrasound and the impact hammer on the four tested bridges.
\end{abstract}

Key words: Rebound hammer, ultrasound, compressive strength, nondestructive tests, statistical error analysis.

\section{INTRODUCTION}

Nowadays, reinforced concrete is globally the most widely used construction material, and the use of NonDestructive Testing (NDTs) to measure its properties in situ, without causing damage, and to monitor structural integrity, is employed to determine the useful lifespan of structures (Hamidian et al., 2012). The use of a combination of nondestructive methods can improve the reliability of results, which are then closer to the true values when compared with measurements made using individual tests alone (Shariati et a., 2011; Breysse, 2009, 2012; Sbartai et al., 2012). Such combined methods have a long history of use for investigating damage, cracks, fissures, void spaces, decreased mechanical strength, and other defects related to the deterioration of concrete (Shariati et al., 2011). Some of the available technical guidelines (ABNT, 1995; BS, 1986) suggest that the 


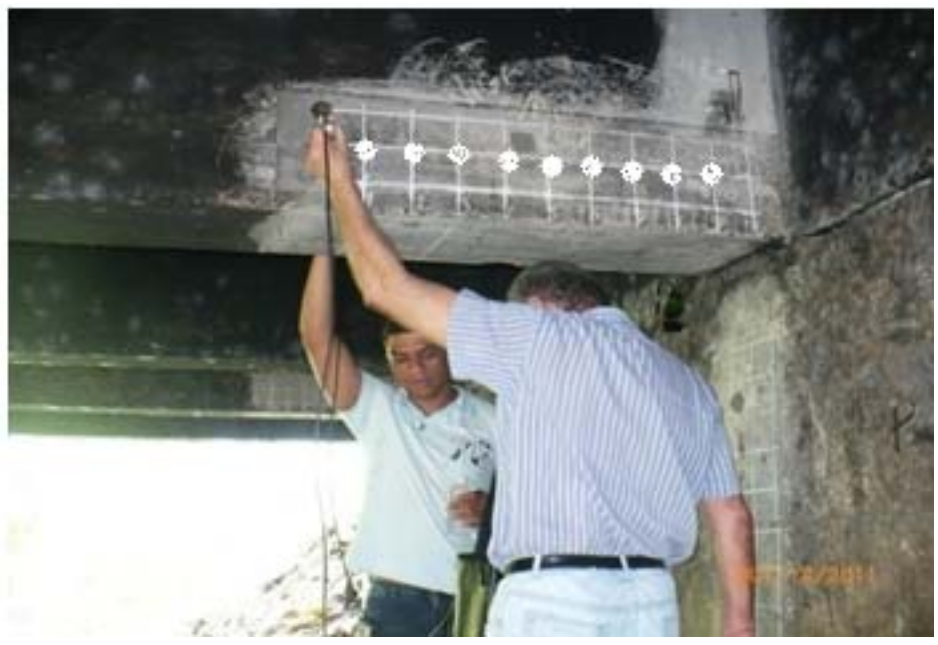

Figure 1. Illustration of the rectangular network used for measurements by impact hammer and ultrasound in a region of maximum stress of a bridge stringer.

compressive strength of concrete can be estimated using curves describing the correlation between the values obtained from Non-Destructive Testing (NDTs) and destructive compressive tests. Although the mechanical strength of concrete shows no direct relationship with surface hardness or ultrasound propagation velocity, empirical models have been developed using regression techniques to describe the correlations between strength and the results obtained using the two techniques (Hamidian et al., 2012; Shariati et al., 2011; Machado et al., 2009; Mature, 2011; Almeida, 1993; Mohammed et al., 2011). This is because the strength of concrete is well correlated to the stiffness and the surface hardness of concrete. The relation between ultrasound, rebound hammer and compressive strength is then indirect relation. The rebound hammer method has been used in other areas such as in saligna eucalyptus wood pieces to assess trends of correlations between compressive strength to normal and parallel to the fibers (Soriano et al., 2011).

Comparison of the results of experimental measurements requires confidence in the reliability of the data obtained, especially when it is proposed to combine techniques that are very different, such as ultrasound and rebound hammer. This, together with interpretation of the measurements, can be achieved by combining experimental procedures with appropriate statistical techniques. Even when experiments are repeated under the same conditions, the results may not be identical or even comparable. The existence of experimental error is systematic or random, may lead to values that vary widely (Taylor, 2012; Box et al., 2005; Severo et al., 2011). In all areas of knowledge, including that of NonDestructive Testing (NDTs), it is common to find studies in which adequate statistical treatment of the data has not been applied, in many cases leading to erroneous conclusions (Cerqueira et al., 1999; Larenti, 2003). Straightforward statistical techniques that are available for this purpose include the Student's t-test and Fisher's F-test (Nguyen et al., 2013). Although simple, these tests can provide reliable interpretation of the extent of any experimental errors (Cerqueira et al., 1999; Larentis et al., 2003).

In the present work, measurements employing ultrasound and rebound hammer, together with statistical tests to evaluate the reliability of the results, were employed to determine the mechanical compressive strength of reinforced concrete at four bridges located in the city of Aracaju (Sergipe State, Brazil).

\section{METHODOLOGY}

\section{Measurement procedures}

A total of 1360 ultrasound measurements and 680 impact measurements were made at pillars and stringers of the four bridges, at structurally strategic locations with maximum internal loadings. The guidelines used as references in the test procedures were NBR 7584/95 (ABNT, 1995), NM 78:96 (Mercosur, 1996), and ASTM C 805-85, (ASTM, 1993) for surface hardness, and NBR 8802 (ABNT, 1994) and ASTM C 597, (ASTM, 2002) for the propagation of ultrasound in concrete. The equipment used for the impact tests was a SilverSchmidt-type mechanical hammer with impact energy of $2.2 \mathrm{Nm}$, while the ultrasound tests employed a USLab instrument equipped with a pair of flat $54 \mathrm{KHz}$ transducers. The impact tests were made horizontally and perpendicularly to the surfaces of the concrete, and the ultrasound tests used direct transmission between opposite faces. The use of all equipment followed standardized calibration routines.

Prior to beginning the final tests, possible local interferences were minimized by performing scans to locate reinforcements underlying the locations that were subsequently tested, and by cleaning the sampling regions in order to smooth the surfaces and reduce surface deposits of carbonates. A manual Profoscope metal reinforcement detector was used. Figure 1 illustrates the 

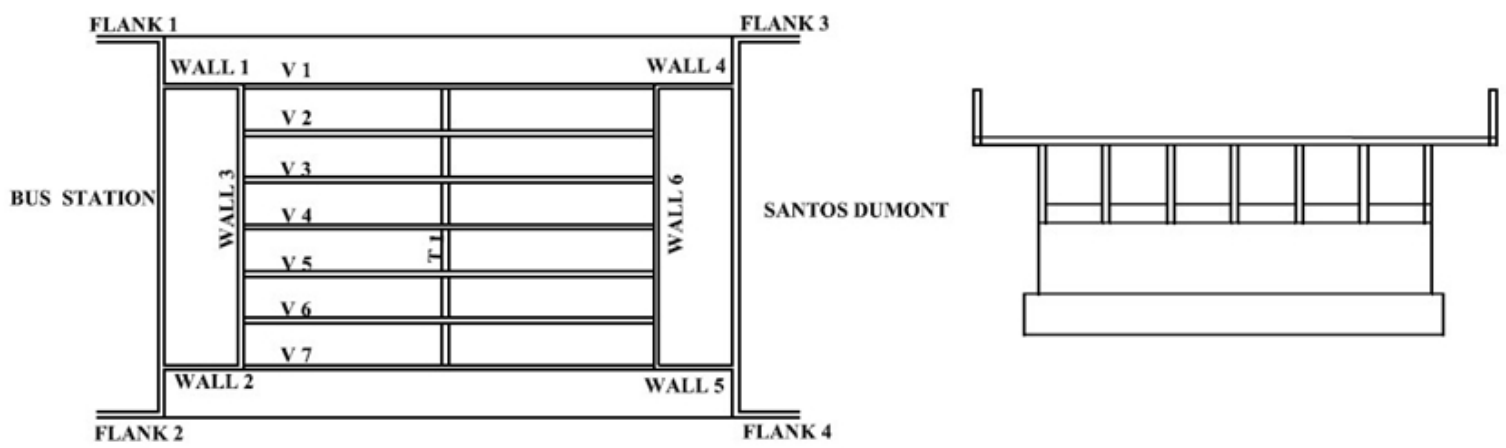

Figure 2. Illustration of structural design for one of the bridges.

demarcation of a rectangular network of 10 points, and Figure 2 shows a schematic of the structural characteristics of one of the bridges tested.

The ultrasound and impact measurements were made at the same 10 points of each network. Two measurement methods were used in this case study: (1) Single ultrasound and rebound hammer measurements at each point of the network, as recommended in NBR 7584/95 (ABNT, 1995), totaling a set of 20 measurements in each network of 10 points; (2) Measurements at each of the 10 points of a series of rectangular networks, with 10 replicates in the ultrasound tests and five replicates in the impact tests, totaling a set of around 150 measurements.

Due to the concrete being a heterogeneous material, the reapplication of ultrasound and rebound hammer measurements were made aiming to increase the reliability of outcomes, since only one measurement at each point would be equivalent to consider it homogeneous, which does not correspond to the actual characteristics of the concrete. The maximum number of impacts was established after compatibilizing the rigidity of the structural part of the test with the impact energy of the hammer. The ten measurements with ultrasound at each point were set to reliably assess the experimental operator errors, mainly because of the various influences of concrete.

\section{Data analysis}

The data obtained using Method (1) were analyzed considering only the arithmetic average, following the recommended guidelines (ABNT, 1995). In the case of Method (2), the data were statistically analyzed using the Student's t-test and Fisher's F-test (Schwaab and Pinto, 2007). The objective of the t-test was to identify the existence of a common measurement interval, hence generating a statistical level of confidence for the measurement. The confidence interval for each measurement was calculated using the following equation (Schwaab and Pinto, 2007):

$$
t_{N-1}=\frac{\bar{x}-\mu}{\frac{s}{\sqrt{N}}}
$$

where $N$ is the number of replicates or experiments, $\bar{X}$ is the sampling mean, $s$ is the standard deviation, and $t_{N-1}$ is the value of the $t$ distribution with $N-1$ degrees of freedom and a $95 \%$ confidence level.

Using the variances of the measurements performed by the two techniques, the behavior of the errors was analyzed by applying the
F-test, described by:

$$
F_{x y} *=\frac{\sigma_{x}^{2}}{\sigma_{y}^{2}}
$$

where $F_{x y}{ }^{*}$ is the calculated value of $\mathrm{F}$, and $\sigma_{x}^{2}$ and $\sigma_{y}^{2}$ are the variances of the sampling groups. The value of $F_{x y}{ }^{*}$ obtained was then compared with the limits established using:

$$
\left(\frac{1}{F_{100-p \%}}, v_{2}, v_{1}\right)<F^{*}<\left(F_{p \%}, v_{1}, v_{2}\right)
$$

where $v_{1}$ and $v_{2}$ represent the degrees of freedom of the sampling sets analyzed, and $F_{p \%}$ and $F_{100-p \%}$ are the tabulated values of $F$ for a $95 \%$ confidence level. Hence, for a $95 \%$ level of confidence $(p$ $=2.5 \%$ ), if the value of $\mathrm{F}^{*}$ (the calculated $\mathrm{F}$ value) was greater than $\mathrm{F}_{0.025}$ or smaller than $\frac{1}{F_{0,975}}$, and therefore lay outside the tabulated limit, the errors were not equivalent. It should be pointed out that in all these statistical tests, it was assumed that the experimental data showed normal distributions (Almeida, 1993).

\section{RESULTS}

\section{Using measurement method (1)}

The measurements made using the rebound hammer and ultrasound techniques at one of the bridges are shown in Figure 3( $a$ and $b$ ) and 4 ( $a$ and b), respectively. For each pillar, the mean value was calculated from single measurements made at each of the ten sampling points in the network. Similar results were obtained for the other three bridges.

\section{Using measurement method (2)}

Figures 5 to 7 show the values obtained for the pillars 

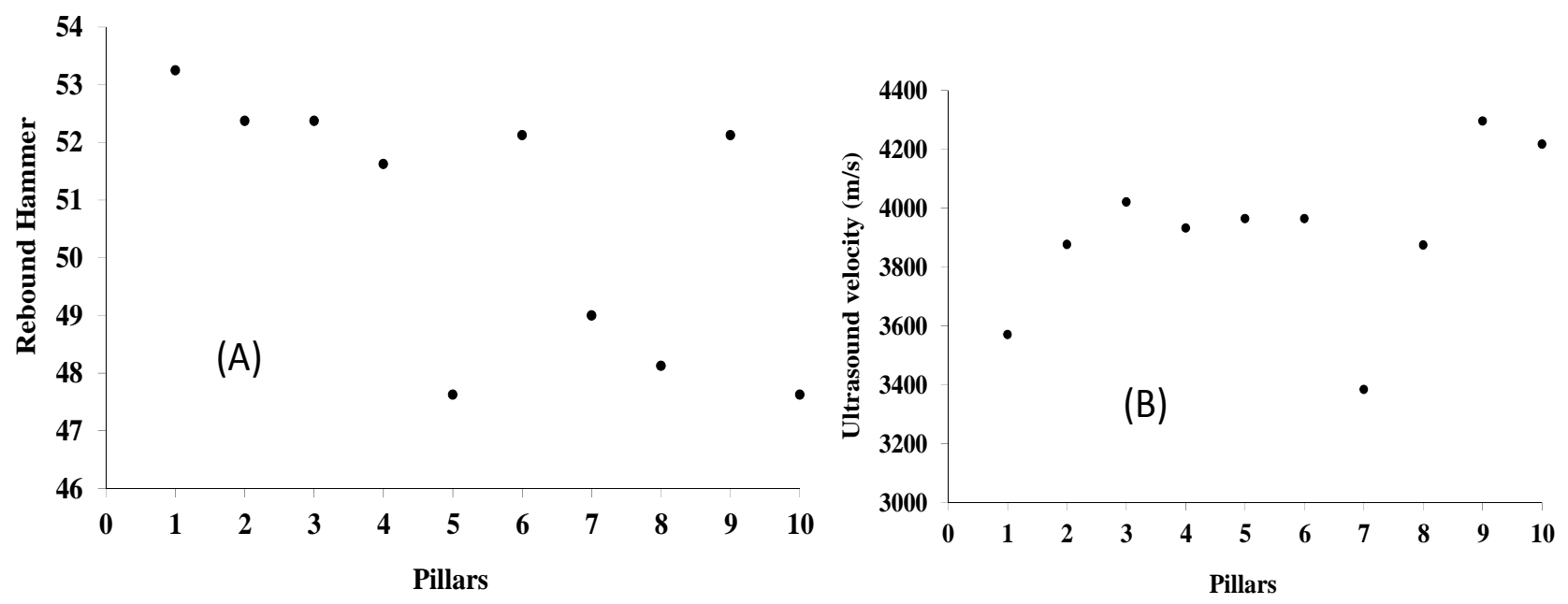

Figure 3. Mean values using data from the method (1) at Bridge 1: (a) Rebound impact; (b) Ultrasound.
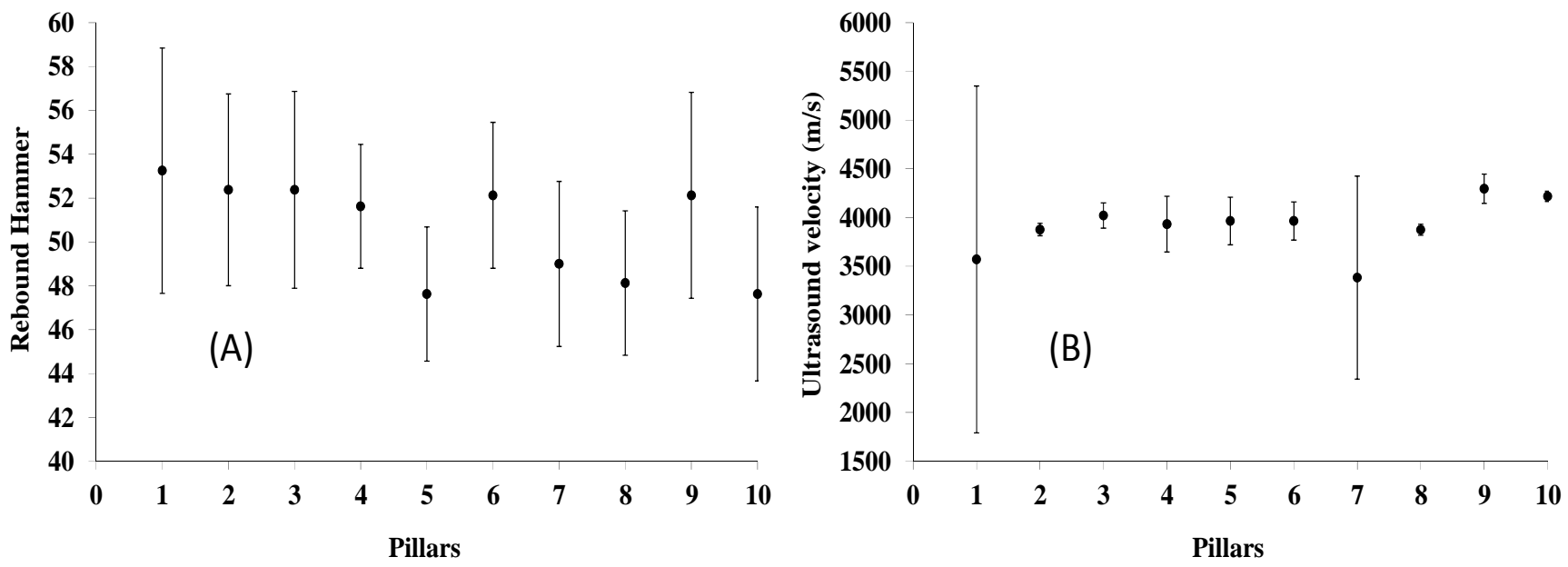

Figure 4. Mean values and confidence intervals with application of the Student's t-test using data from the method (1) at Bridge 1: (a) Rebound impact; (b) Ultrasound.

and stringers of the bridges tested, using ten ultrasound measurements at each of the ten points of the sampling network, followed by five impact measurements at each sampling point, instead of only a single measurement at each point as recommended in the guidelines (ABNT, 1995; Mercosur, 1996). The five impact measurements at each point disobeyed the ABNT NBR 7584 guideline (subsection 4.3.5), which states: "more than one impact at the same point is not permitted. If this occurs, the second reading should not be considered in calculation of the results". In the present case, the pillars and stringers were highly rigid, and the impact energy delivered by the hammer did not cause phenomena such as resonance and vibration, or any significant dissipation of energy. After each impact at the same point, the mark left on the surface was checked for any significant fractures or fissures, as described in subsection 5.6.5 of NM 78:96
(Mercosur, 1996). No such features were observed. Figure $5(\mathrm{e})$ is the following legend to Figures 5 to 7 , relating to items (c) and (d), and the P-X-Y notation means the value of the pillar $F$ calculated between $X$ and $Y$, in the respective figures. The red and black bars represent the tabulated values of the $F$ test.

\section{DISCUSSION}

\section{Using measurement method (1)}

The measurements made using the rebound hammer and ultrasound techniques at one of the bridges are shown in Figure 3(a) and (b), respectively. The rebound hammer measurements exceeded an index value of 47 for all pillars. According to the correlation curve for the 

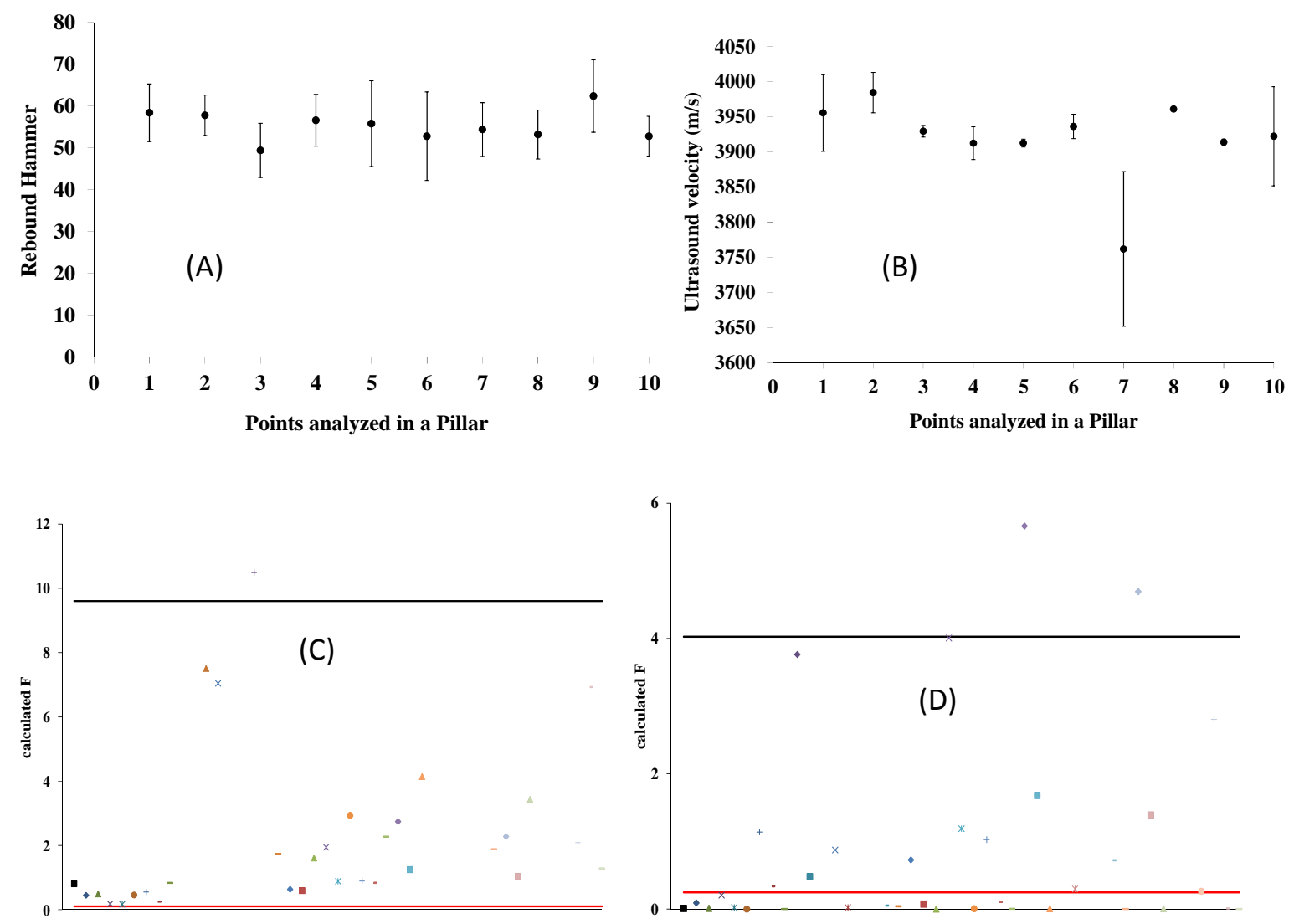

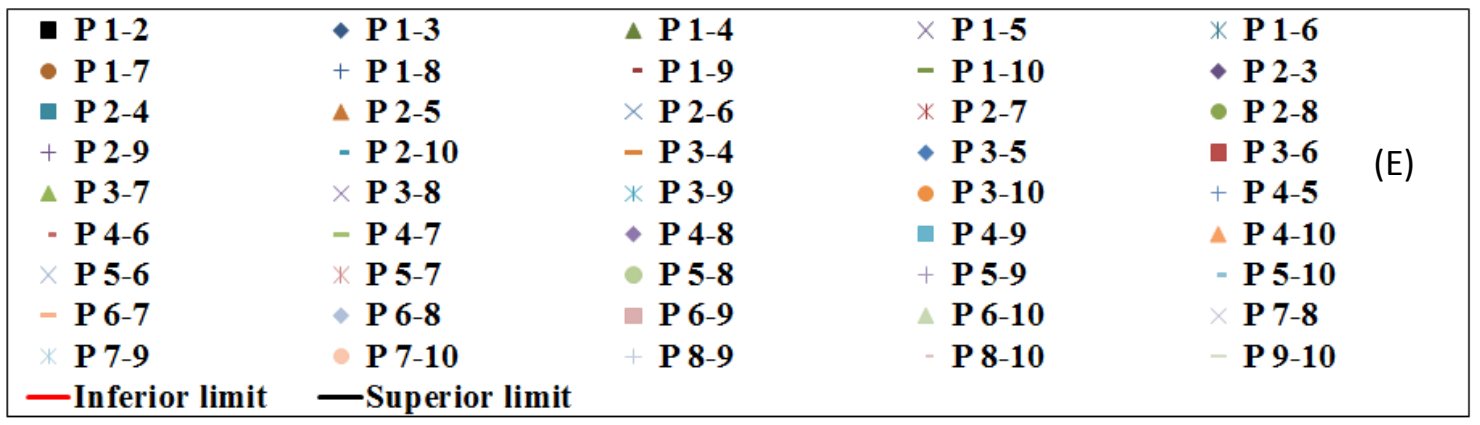

Figure 5. Measurements at a pillar of Bridge 1 for the method 2. a) Rebound Impact; b) Ultrasound; Application of the F-test to the impact (c) and ultrasound (d) data; e) Legend to Figures 5 to 7, relating to items (c) and (d), where the $\mathrm{P}-\mathrm{X}-\mathrm{Y}$ notation means the value of the pillar Fcalculated

instrument, this represented a compressive strength that exceeded $50 \mathrm{MPa}$. This level of resistance is highly satisfactory in terms of the mechanical performance of the structures tested.

In the case of the ultrasound measurements, no correlation curve was available for the relationship between the resistance and ultrasound velocity. Nonetheless, a mean sound wave propagation velocity of between 3800 and $4000 \mathrm{~m} / \mathrm{s}$ could be classified as excellent, according to the scale proposed by Cánovas (1998), reflecting high strength of the concrete to compression (higher ultrasound velocity corresponds to greater mechanical resistance).

The results obtained from the combined use of the two nondestructive techniques, rigorously following technical guidelines, indicated that the quality of the structures and their mechanical resistance to compression were satisfactory in terms of structural safety. However, considerable care must be taken in using mean values alone during the analysis of results. Although this practice is widely reported in the literature, and is common sense in professional activities, the mean does not necessarily represent the most probable experimental value and may not accurately reflect physical reality. Taken alone, the 

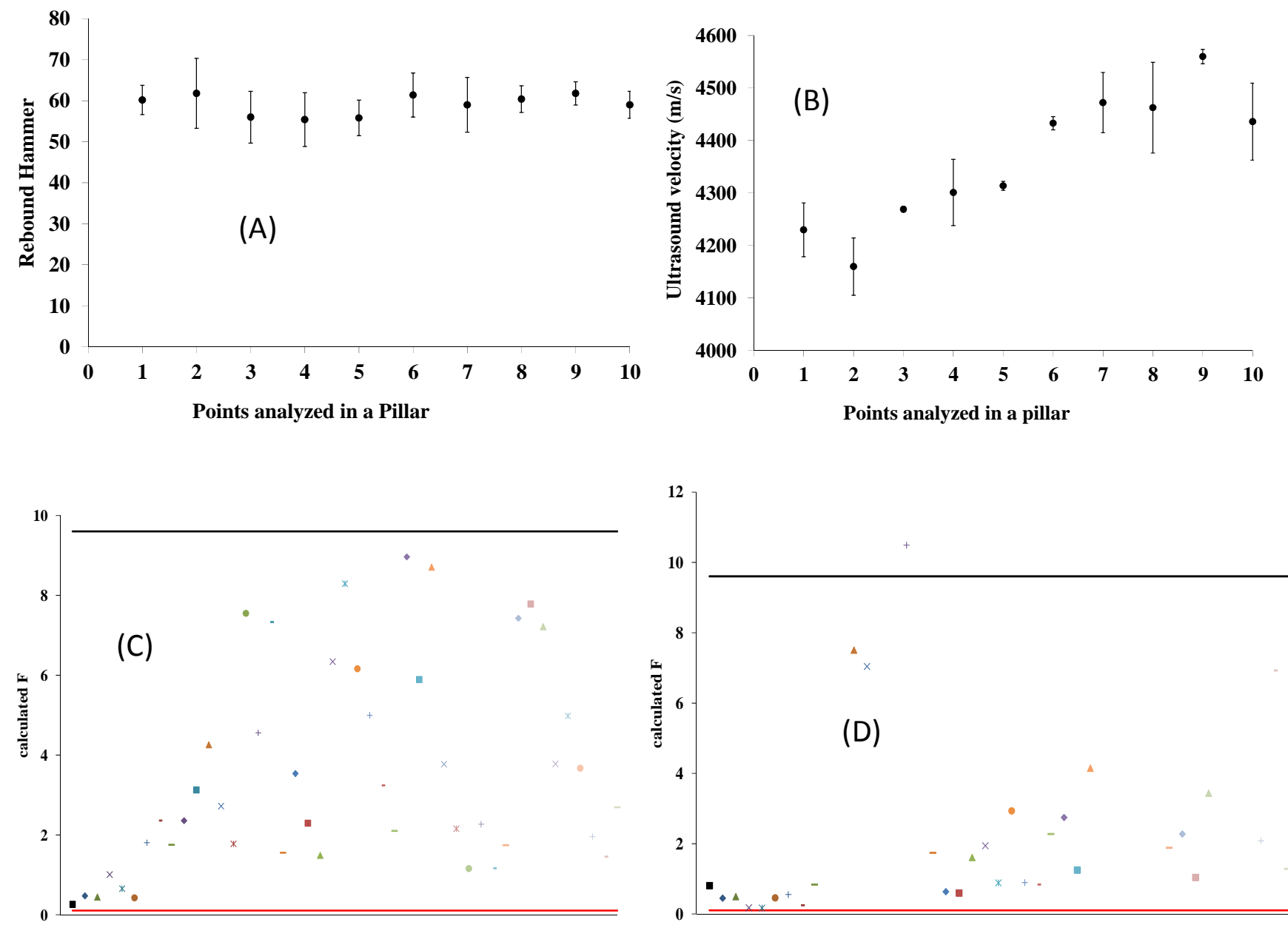

Figure 6. Measurements at a pillar of Bridge 2 for the method 2. a) Rebound Impact; b) Ultrasound; Application of the F-test to the impact (c) and ultrasound (d) data; Legend is available in the Figure 5(e).

mean value has no significance; the associated error must also be taken into consideration (Schwaab and Pinto, 2007). When the same results were analyzed considering the confidence intervals (Figures 4(a) and (b)), there were clear implications for the quality of the concrete of the pillars. The ultrasound results obtained considering only the mean (Figure 3(b)) were indicative of optimum ultrasound velocities (Cánovas, 1998). Meanwhile, observation of the variability of the measurements around the mean (the confidence interval) for pillars 1 and 7 (Figure 4(b)) revealed that in these cases, the quality of the concrete could be classified as being between optimum and satisfactory, according to the scale given by Cánovas (1998). Despite the importance of considering uncertainties in the measurements, in day-to-day practice these are often ignored (Taylor, 2012), which can lead to interpretations that are erroneous.

In addition to the obvious consequences that could occur when results are analyzed using only mean values, the Method 1 has another failing: it considered the sum of the values for the sampling network. For the procedure adopted it would not be possible to use the values sum, the mean and the confidence interval, which demand a homogeneous sample. It could not provide a statistical guarantee that the values obtained throughout the sampling network were the same, especially because is unlikely that concrete could be homogeneous throughout the pillar or stringer.

In order to use the sum of these measurements, they should be repeated at each point in the sampling network, in order to permit subsequent use of statistical procedures (t-tests and F-tests) to evaluate the homogeneity of the means and the errors (this is discussed below for the results obtained using the second measurement protocol). Analysis of the quality of concrete can therefore be compromised either by adopting a surface measurement technique, such as rebound impact tests or even by failing to apply a simple statistical analysis. At the present case rebound impact indicated similar mechanical behavior for all the pillars (Figure 4(a)), while the ultrasound data clearly identified 

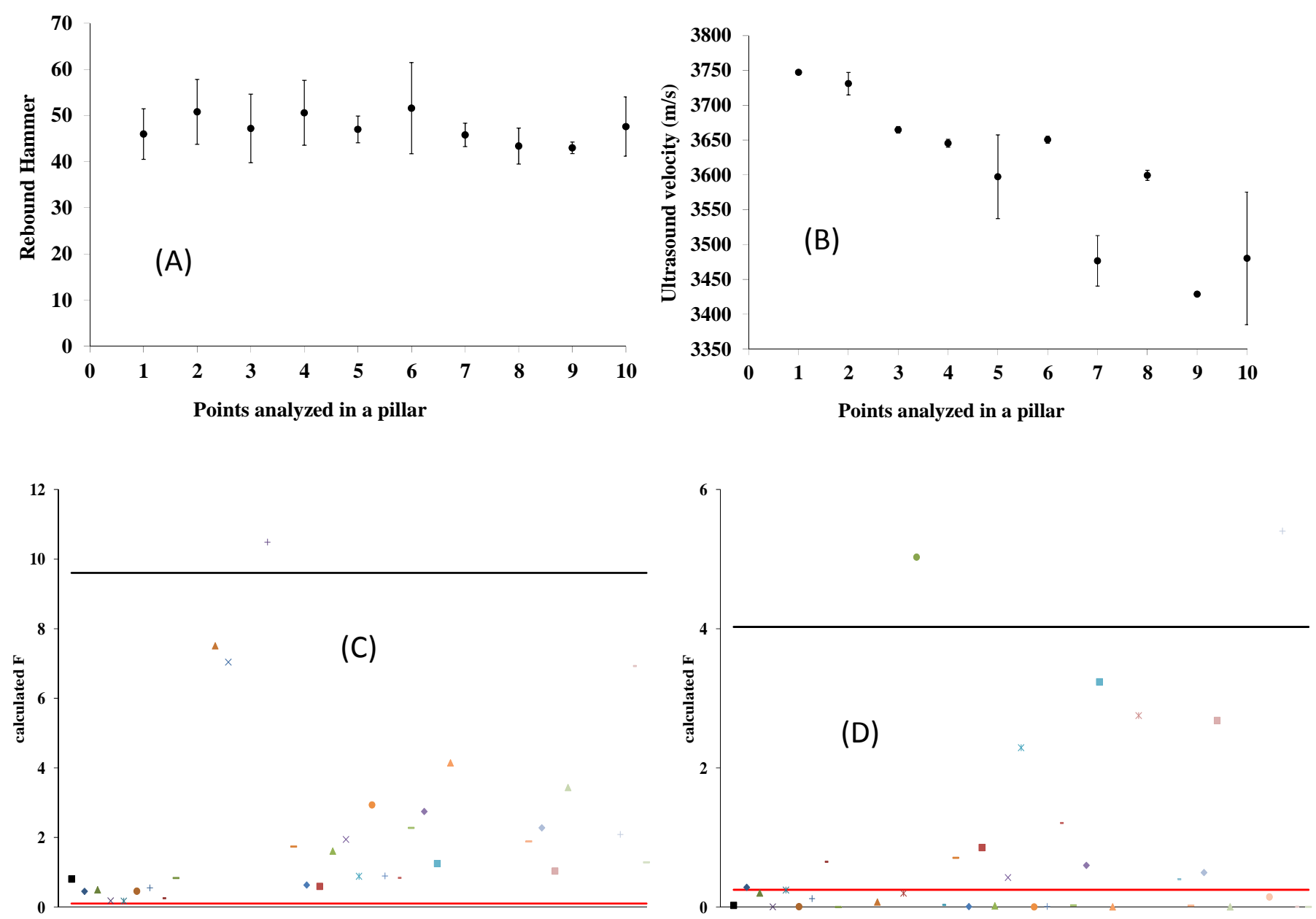

Figure 7. Measurements at a pillar of Bridge 3 for the method 2. a) Rebound Impact; b) Ultrasound; Application of the F-test to the impact (c) and ultrasound (d) data; Legend is available in the Figure 5 e).

problems in the quality of the concrete in pillars 1 and 7 , compared to the other pillars (Figure 4(b)). The limitations of the Method 1 were the motivation to propose a different set of measurements, Method 2, to obtain a statistical guarantee for the results.

\section{Using measurement method (2)}

In the case of the rebound hammer measurements, the confidence intervals of the means overlapped (Figures 5(a), 6(a), and 7(a)). Based on the t-test with 95\% confidence, it could therefore be concluded that the measurements at the different pillars were equivalent in terms of the mean. Nonetheless, in using the sum of all the values obtained for the sampling network, it was necessary to evaluate the errors using the F-test (Figures $5(\mathrm{c}), 6(\mathrm{c})$, and 7 (c). The values of $F_{\text {calculated }}$ lay within the tabulated limits (Figure 8), indicating that the errors were equivalent, so it was therefore possible to use the sums of all the measurements.
The ultrasound results showed a very different behavior compared to the rebound hammer data, as shown in Figures 5(b), 6(b), and 7(b). The measurements at the different points of the sampling network were clearly not homogeneous. Considering only a single repletion of each measurement was not possible to sum all the ultrasound results to obtain a representative mean. In addition to the means not being equivalent for the ultrasound data, the errors also showed the same behavior. It can be seen from Figures 5(d), 6(d), and 7(d) that the calculated values of $F$ lay outside the tabulated limits, indicating that the variability was different for each point on the pillar. According to the impact data, the concretes were homogeneous, with satisfactory performance in terms of structural safety and quality of the construction. The conclusion of the technical diagnosis would be that the structures were acceptable without interventions. On the other hand, the ultrasound results revealed divergent behavior, highlighting the fact that the structures were not homogeneous throughout their composition. Internal defects that can lead to 

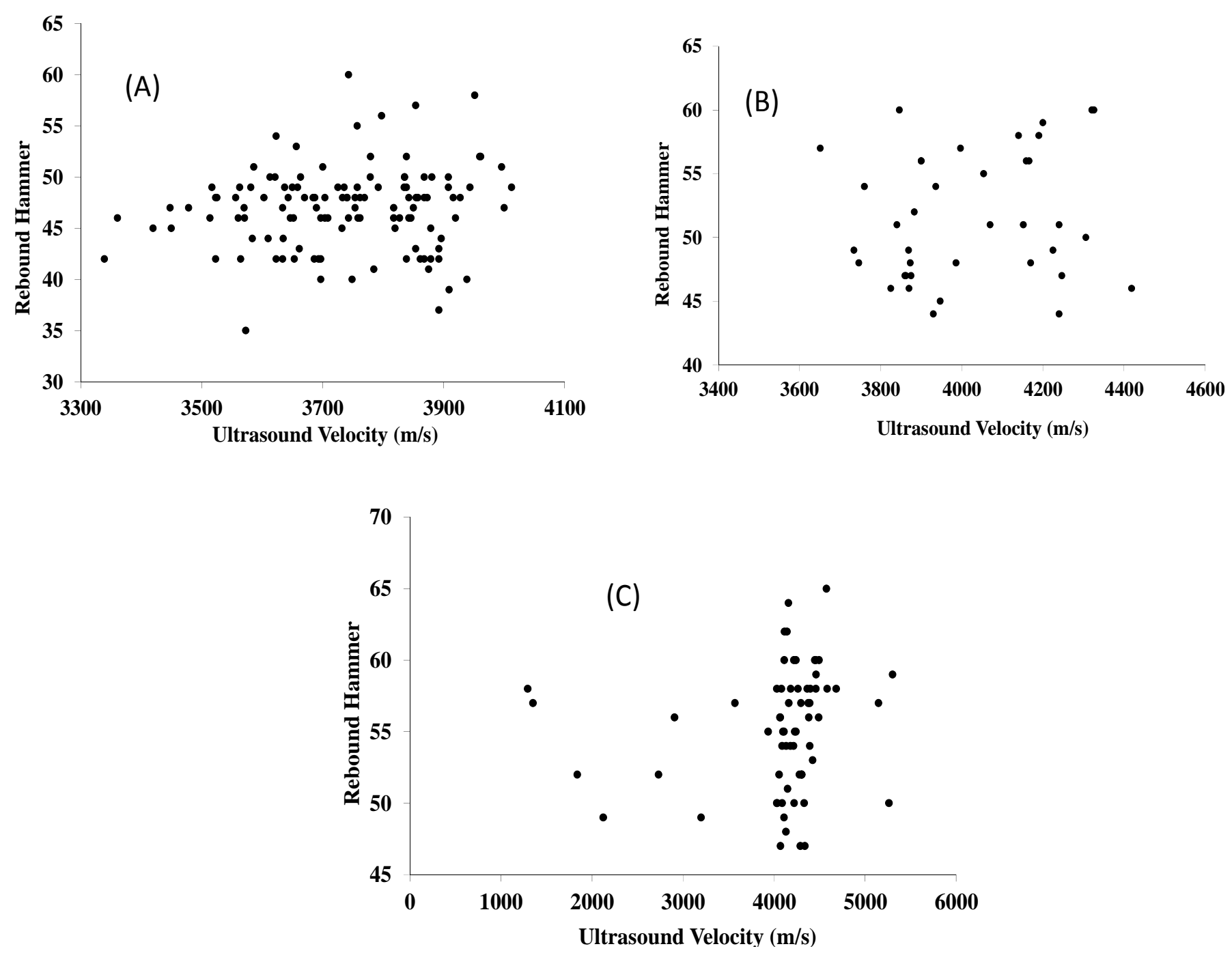

Figure 8. Scatter plots of the means obtained using ultrasound and rebound hammer measurements at the three bridges: bridge 1 (a); bridge 2 (b) and bridge 3 (c).

unsatisfactory structural conditions include the presence of void spaces, cracks, and corrosion. The analysis of experimental errors substantiate this conclusion.

\section{Analysis of the correlation between the rebound hammer and ultrasound data}

The distributions of the points representing the means for the measurements made at the bridges using ultrasound and rebound are shown in Figure 8. In contrast to earlier findings (Almeida, 1993), the distributions obtained here using real field measurements at four bridges indicated that it was not possible to establish a correlation model describing the relation between the rebound hammer and ultrasound techniques. In previous field measurements, Hamidian et al., (2012) obtained correlation coefficients $\left(R^{2}\right)$ of 0.0275 and 0.0115 , indicating a lack of correlation between ultrasound and rebound hammer methods. This lack of correlation can largely be explained by the obvious differences between the principles of the techniques and the physical properties measured, together with the errors and uncertainties inherent in any method, whose variability during the course of measurements should not be ignored in order to avoid compromising the reliability of the results.

\section{Conclusions}

The use of combined nondestructive techniques in concrete quality evaluation is recommended, as this procedure can increase the reliability of results in the presence of variable experimental errors. Meanwhile, consideration should be given to the fact that experimental errors can vary significantly across the areas tested. The 
results presented here demonstrate that it is not possible to achieve a reliable technical evaluation, whether using ultrasound or rebound, without taking into account the variability of the uncertainties (errors) during the course of the test procedures. Failure to considerer these uncertainties, could lead to erroneous conclusions during the evaluation of concrete quality and an inability to predict the safety of structures.

In contrast to other studies, no correlation was observed between the results of measurements of conventional concretes made using rebound and ultrasound. Certain aspects of the NBR 7584 (ABNT, 1995) and NM 78:96 (Mercosur, 1996) guidelines concerning surface hardness may require reappraisal, especially concerning the use of arithmetic means and the drawing of conclusions from tests employing impact hammers to determine the compression resistance of concrete. The present findings suggest that the use of the impact technique should be restricted to the analysis of the surface characteristics of concrete. The method is unable to provide a reliable evaluation of the mechanical properties of structural components as a whole, especially in the absence of statistical tools to determine the levels of uncertainty.

\section{Conflict of Interest}

The author(s) have not declared any conflict of interests.

\section{ACKNOWLEDGEMENTS}

The authors are grateful for the support provided by the Brazilian agencies: PRONEX/CNPq/FAPITEC, CAPES/PROENGENHARIA/PROCADA and INOVATEC/FINEPE for their financial support.

\section{REFERENCES}

Almeida IR (1993). Employment rebound hammer and ultrasound to effect a qualitative evaluation of high performance concrete. Brazil Federal Fluminense University. PhD Thesis, $139 \mathrm{p}$.

American Society for Testing and Materials (1993). Test for rebound number of hardened concrete. ASTM C 805-85.

American Society for Testing and Materials (2002). Standard test method for pulse velocity through concrete. ASTM C 597.

Brazilian Association of Technical Standards (1994). Hardened concrete - Determination of the propagation speed of the ultrasonic wave. ABNTNBR 8802.

Brazilian Association of Technical Standards (1995). Evaluation of surface hardness. ABNT NBR 7584

Breysse D, Soutsos M, Felicetti R, Krause M, Lataste JF, Moczko A (2009). How to improve the quality of concrete assessment by combining several NDT measurements. Nantes, France NDTCE'09, Non-destructive Testing in Civil Engineering. June 30th-July 3rd.

Breysse AD (2012). Non-destructive evaluation of concrete strength: A historical review and new perspective by combining NDT methods. Constr. Build. 33:39-163. http://dx.doi.org/10.1016/j.conbuildmat.2011.12.103
British Standards (1986). Recommendations for surface hardness tests by the rebound hammer. BS 1881: Part 202.

Box GEP, Hunter WG, Hunter JS (2005). Statistics for Experimenters. New York John Wiley \& Sons. 2nd edition. PMCid:PMC1273458

Cánovas MF (1998). Pathology and Therapy of Concrete. Brazil Ed. PINI. $522 \mathrm{p}$.

Cerqueira HS, Rawet R, Pinto JC (1999). The influence of experimental errors during laboratory evaluation of FCC catalysts. Applied Catalysis A. 181:209-220. http://dx.doi.org/10.1016/S0926860X(99)00004-6

Hamidian M, Shariati A, Khanouki MMA, Sinaei H, Toghroli A,Nouri K (2012). Application of Schmidt rebound hammer and ultrasonic pulse velocity techniques for structural health monitoring. Sci. Res. Essays 7(21):1997-2001.

Larentis AL, Bentes Jr. AMP, Resende NS, Salim VMM, Pinto JC (2003). Analysis of experimental errors in catalytic tests for production of synthesis gas. Appl. Catal. A. 242:365-379. http://dx.doi.org/10.1016/S0926-860X(02)00525-2

Machado MD, Shehata LCD, Shehata IAEM (2009). Correlation curves to characterize concretes used in Rio de Janeiro- Brazil by means of non-destructive tests. Brazil Ibracon Struc. Mater. J. 2(2):100-123.

Mahure NV, Vijh GK, Sharma P, Sivakumar N, Ratnam M (2011). Correlation between pulse velocity and compressive strength of concrete. Int. J. Earth Sci. Eng. 4(6):871-874.

Mercosur Committee for Standardization (1996). Hardened concrete Evaluation of surface hardness by rebound hammer. NM 78:96.

Mohammed BS, Azmi NJ, Abdullahi M (2011). Evaluation of rubbercrete based on ultrasonic pulse velocity and rebound hammer tests. $\begin{array}{llll}\text { Constr. Build. } & \text { 25:1388-1397. }\end{array}$ http://dx.doi.org/10.1016/j.conbuildmat.2010.09.004

Nguyen NT, Sbartai ZM, Lataste JF, Breysse D, Bos F (2013). Assessing the spatial variability of concrete structures using NDT techniques- laboratory tests and case study. Constr. Build. Mater 49:240-250. http://dx.doi.org/10.1016/j.conbuildmat.2013.08.011

Schwaab M, Pinto JC (2007). Analysis of Experimental Data 1: Fundamentals of Statistics and Parameter Estimation. E-papers. Brazil, Rio de Janeiro. http://translate.googleusercontent.com/translate $c$ ?depth=1\&hl=en\&p rev=/search\%3Fq\%3DSchwaab,\%2BM.,\%2BPinto,\%2BJ.C\%2B(200 7)\&rurl=translate.google.com.ng\&sl=pt-BR\&u=http://www.epapers.com.br/produtos.asp\%3Fcodigo_produto\%3D1253\&usg=ALk Jrhi1vpzKPVpgYT2j-PMoScdvnFVDtw

Severo Jr. JB, Pinto JC, Ferraz HC, Alves TLM (2011). Analysis of experimental errors in bioprocesses. 1. Production of lactobionic acid and sorbitol using the GFOR (glucose-fructose oxidoreductase) enzyme from permeabilized cells of Zymomonas mobilis. J. Industr. Microbiol. Biotechnol. 38:1575-1585. http://dx.doi.org/10.1007/s10295-011-0948-1; PMid:21328074

Shariati M, Ramli-Sulong NH, Arabnejad KHMM, Shafigh P, Sinaei H (2011). Assessing the strength of reinforced concrete structures through ultrasonic pulse velocity and Schmidt rebound hammer tests. Sci. Res. Essays 6(1):213-220.

Soriano J, Gonçalves R, Bertoldo C, Trinca AJ (2011). Applications rebound hammer test pieces Saligno eucalyptus. Brazil. J. Agric. Environ. Eng. 9(3):322-328.

Taylor JR (2012). Introduction to Error Analysis - The Study of Uncertainties in Physical Measurements. Bookman ( $\left.2^{\mathrm{a}} \mathrm{ed}\right)$.

Sbartai ZM, Breysse D, Larget M, Balayssac JP (2012). Combining NDT techniques for improved evaluation of concrete properties. Cement and Concrete Composites. 34:725-733. http://dx.doi.org/10.1016/j.cemconcomp.2012.03.005 